\title{
Parallel Evolution of Serotonergic Neuromodulation Underlies Independent Evolution of Rhythmic Motor Behavior
}

\author{
Joshua L. Lillvis and Paul S. Katz \\ Neuroscience Institute, Georgia State University, Atlanta, Georgia 30303-5030
}

\begin{abstract}
Neuromodulation can dynamically alter neuronal and synaptic properties, thereby changing the behavioral output of a neural circuit. It is therefore conceivable that natural selection might act upon neuromodulation as a mechanism for sculpting the behavioral repertoire of a species. Here we report that the presence of neuromodulation is correlated with the production of a behavior that most likely evolved independently in two species: Tritonia diomedea and Pleurobranchaea californica (Mollusca, Gastropoda, Opisthobranchia, Nudipleura). Individuals of both species exhibit escape swimming behaviors consisting of repeated dorsal-ventral whole-body flexions. The central pattern generator (CPG) circuits underlying these behaviors contain homologous identified neurons: DSI and C2 in Tritonia and As and A1 in Pleurobranchaea. Homologs of these neurons also can be found in Hermissenda crassicornis where they are named CPT and C2, respectively. However, members of this species do not exhibit an analogous swimming behavior. In Tritonia and Pleurobranchaea, but not in Hermissenda, the serotonergic DSI homologs modulated the strength of synapses made by C2 homologs. Furthermore, the serotonin receptor antagonist methysergide blocked this neuromodulation and the swimming behavior. Additionally, in Pleurobranchaea, the robustness of swimming correlated with the extent of the synaptic modulation. Finally, injection of serotonin induced the swimming behavior in Tritonia and Pleurobranchaea, but not in Hermissenda. This suggests that the analogous swimming behaviors of Tritonia and Pleurobranchaea share a common dependence on serotonergic neuromodulation. Thus, neuromodulation may provide a mechanism that enables species to acquire analogous behaviors independently using homologous neural circuit components.
\end{abstract}

\section{Introduction}

Behaviors are produced by neural circuits whose outputs depend upon the neuronal and synaptic properties of their components. Neuromodulation can alter those properties and thereby select a particular functional output (Harris-Warrick and Marder, 1991; Katz, 1999; Katz and Calin-Jageman, 2008). Thus, species differences in behavior might be caused by differences in neuromodulation (Arbas et al., 1991; Katz and Harris-Warrick, 1999). Conversely, similar neuromodulatory actions in disparate species might underlie independent evolution of analogous behaviors (Young and Wang, 2004).

Tritonia diomedea and Pleurobranchaea californica are two sea slug species within the monophyletic clade Nudipleura (Mollusca, Gastropoda, Opisthobranchia) (Waegele and Willan, 2000; Bouchet et al., 2005) that exhibit similar escape swimming behav-

\footnotetext{
Received Sept. 2, 2012; revised Dec. 2, 2012; accepted Dec. 5, 2012

Author contributions: J.L.L. and P.S.K. designed research; J.L.L. performed research; J.L.L. and P.S.K. analyzed data; J.L.L. and P.S.K. wrote the paper.

This work was supported by NSF Grants IOS-1120950 and IOS-1011476. We thank Stephen Kempf for supplying the $\mathrm{SCP}_{\mathrm{B}}$ antibody as well as Ronald Calabrese, Charles Derby, and Anne Murphy, Charuni Gunaratne, and Akira Sakurai for helpful comments on these experiments and this manuscript.

The authors declare no competing financial interests.

Correspondence should be addressed to Dr. Paul S. Katz, Neuroscience Institute, Georgia State University, P.O. Box 5030, Atlanta, GA 30303-5030. E-mail: pkatz@gsu.edu.

J.L. Lillvis' present address is Research Institute of Molecular Pathology, Dr. Bohrgasse 7, A-1030 Vienna, Austria. DOI:10.1523/JNEUROSCI.4196-12.2013

Copyright $\odot 2013$ the authors $\quad 0270-6474 / 13 / 332709-09 \$ 15.00 / 0$
}

iors consisting of alternating dorsal and ventral whole-body flexions (Willows, 1967; Gillette et al., 1991). The central pattern generators (CPGs) underlying swimming contain homologous identified neurons. Included is a set of three serotonergic neurons, named DSI $_{\mathrm{A}-\mathrm{C}}$ (DSI) in Tritonia (Getting et al., 1980) and $\mathrm{As}_{1-3}$ (As) in Pleurobranchaea (Jing and Gillette, 1999). The CPGs also contain homologous peptidergic neurons called C2 in Tritonia (Getting, 1977; Taghert and Willows, 1978) and A1 in Pleurobranchaea (Jing and Gillette, 1995). As previously shown (Getting et al., 1980; Jing and Gillette, 1999), these neurons exhibit similar bursting activity during swim motor patterns (Fig. 1). Despite the similarities in the behavior and neural mechanisms, phylogenetic evidence suggests that the dorsal-ventral swimming behaviors of Tritonia and Pleurobranchaea evolved independently from nonrhythmic neural circuitry present throughout the Opisthobranchia (Katz et al., 2001; Newcomb et al., 2012).

In Tritonia, the serotonergic DSI modulates C2 synaptic strength (Katz et al., 1994; Katz and Frost, 1995b). This intrinsic neuromodulation appears to be necessary for the production of the swimming behavior; the serotonin $(5-\mathrm{HT})$ receptor antagonist methysergide, which blocks this synaptic modulation (Katz and Frost, 1995a), also blocks the swimming behavior and the swim motor pattern in the isolated brain (McClellan et al., 1994). Moreover, blocking G-protein coupled signaling in C2, which appears to mediate DSI modulation of C2 synaptic strength, also inhibits the swim motor pattern (Clemens and Katz, 2003). 5-HT 

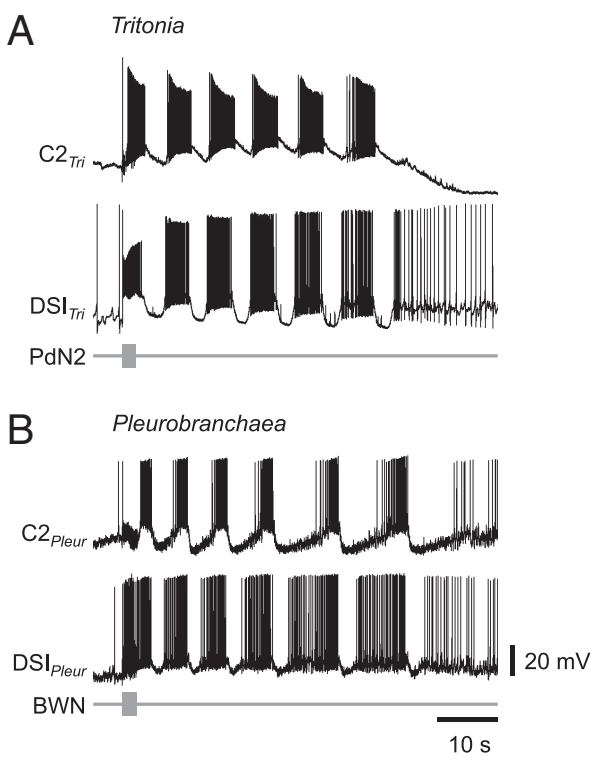

Figure 1. Examples of dorsal-ventral swim motor patterns in isolated Tritonia and Pleurobranchaea brains. Simultaneous intracellular recordings from DSI and (2 show rhythmic bursting that is characteristic of the swim motor patterns in Tritonia $(\boldsymbol{A})$ and Pleurobranchaea $(\boldsymbol{B})$. The motor patterns were elicited by stimulating pedal nerve 2 (PdN2, gray bar) in Tritonia $(\boldsymbol{A})$ and the body wall nerve (BWN, gray bar) in Pleurobranchaea $(\boldsymbol{B})$. Examples are previously unpublished recordings.

induces the swimming behavior and the swim motor pattern in the isolated brain (McClellan et al., 1994). Finally, modeling studies suggest that the enhancement of $\mathrm{C} 2$ synaptic strength is necessary for the production of rhythmic output (Calin-Jageman et al., 2007).

Here, we sought to determine whether the DSI homolog and 5-HT played a similar role in the independently evolved swimming behavior of Pleurobranchaea. We found that the DSI homolog modulated the synaptic strength of the C2 homolog and that serotonergic neuromodulation was necessary for swim production. Furthermore, the extent of this modulation correlated with the robustness of swimming. We found that this modulation was absent in a species that does not exhibit the behavior, Hermissenda crassicornis. Finally, we found that injection of 5-HT induced the swimming behavior in Pleurobranchaea, but not in Hermissenda. These results suggest that serotonergic neuromodulation is responsible, at least in part, for the ability of shared neural circuitry to generate the rhythmic motor pattern in certain species.

\section{Materials and Methods}

Animal collection and maintenance. T. diomedea specimens were obtained from Living Elements. P. californica and $H$. crassicornis specimens were obtained from Monterey Abalone. All species are simultaneous hermaphrodites. Animals were maintained in artificial seawater (Instant Ocean) tanks at a fixed 12:12 light/dark cycle. Tritonia individuals were maintained at $11 \pm 1^{\circ} \mathrm{C}$. Pleurobranchaea and Hermissenda individuals were maintained at $13 \pm 1^{\circ} \mathrm{C}$.

In vivo tests of swimming. To test Pleurobranchaea for swimming, a $10-30 \mathrm{~V}(\sim 1.6-5 \mathrm{~mA})$ shock was applied for $<5 \mathrm{~s}$ to the dorsal body wall. A reflex withdrawal response was reliably observed in response to this stimulus, sometimes accompanied by the initiation of dorsal-ventral swimming, which began with a dorsal body flexion. A dorsal flexion followed by a ventral flexion and a return to a dorsal flexion was defined as a swim cycle. Upon arriving in the laboratory Pleurobranchaea individuals were tested for swimming about every day until they were used for electrophysiological experiments. Tritonia swimming was elicited by applying a $5 \mathrm{M} \mathrm{NaCl}$ salt solution to the dorsal body wall, which reliably induces swimming. Tritonia also reliably swims in response to a $10 \mathrm{~V}$ electric shock (Mongeluzi et al., 1998), but the salt stimulus is more consistent with other studies in the literature. Pleurobranchaea rarely swam in response to the salt stimulus. Hermissenda was stimulated by applying a $5 \mathrm{M} \mathrm{NaCl}$ salt solution to the dorsal body wall, which can induce rhythmic left-right flexions (Lillvis et al., 2012). Electric shock did not cause Hermissenda to swim.

To test for the effect of methysergide or 5-HT on swimming, sizematched individuals were selected and stimulated to swim every $30 \mathrm{~min}$. Animals were injected with a $5 \%$ of total animal volume $10 \mathrm{mg} / \mathrm{L}$ methysergide (dissolved in 1:1000 injection volume of DMSO) solution in artificial seawater. The total volume of the animal was determined by seawater displacement. The $10 \mathrm{mg} / \mathrm{L}$ measurement was based on the total volume plus the $5 \%$ injection volume. Fast Green $(0.2 \%)$ was added to the solution to ensure that the injection spread throughout the body cavity. Control injections consisted of DMSO (1:1000 injection volume) with Fast Green $(0.2 \%)$ in artificial seawater. For 5-HT, animals were injected with a $5 \%$ of total volume $20 \mathrm{~mm} 5$-HT solution in artificial seawater. Fast Green $(0.2 \%)$ was added to ensure the injection spread throughout the body cavity. Control injections consisted of artificial seawater with Fast Green $(0.2 \%)$ at $5 \%$ of total body volume.

Dissection. Individual Tritonia were anesthetized by cooling. Pleurobranchaea and Hermissenda were anesthetized by injection of $0.33 \mathrm{M}$ $\mathrm{MgCl}_{2}$ into the body cavity. A cut was made on the dorsal surface of the body wall near the buccal mass. The brain, consisting of the cerebral, pleural, and pedal ganglia, was removed by cutting all nerve roots. The brain was transferred to a Sylgard-lined dish, where it was superfused at a rate of $\sim 1.0 \mathrm{ml} / \mathrm{min}$ with saline (in $\mathrm{mm}$ ): $420 \mathrm{NaCl}, 10 \mathrm{KCl}, 10 \mathrm{CaCl}_{2}, 50$ $\mathrm{MgCl}_{2}, 11$ D-glucose, and 10 HEPES, pH 7.5.

Connective tissue surrounding the brain was manually removed with forceps and fine scissors while maintaining a temperature of $\sim 4^{\circ} \mathrm{C}$ to reduce neuronal activity. The temperature was raised to $10-11^{\circ} \mathrm{C}$ for Tritonia and $13-14^{\circ} \mathrm{C}$ for Pleurobranchaea and Hermissenda electrophysiological experiments.

Neuron identification and nomenclature. To simplify the nomenclature, we will use the Tritonia neuron names and include a subscript for the species (Tri, Pleur, and Herm) if there is ambiguity as to which species it refers. If there is no subscript, then the property can be assumed to be common to all homologs or the species is clearly defined in context.

$\mathrm{C} 2$ is conspicuous and relatively easy to identify visually across species (Lillvis et al., 2012). In Tritonia, C2 (www.neuronbank.org/Tri0002380) was identified preliminarily using soma position, size, and white appearance. Upon impaling C2 with a microelectrode, its characteristic resting activity, synaptic input, and response to a nerve stimulus further aided identification. In Pleurobranchaea, the axon projection of $\mathrm{C} 2_{\text {Pleur }}$ (A1, www.neuronbank.org/Ple0002601) was confirmed by monitoring the contralateral anterior cerebral-pedal connective and the larger of the pedal-pedal commissures (PP2) (see Newcomb et al., 2006 for nerve nomenclature), which in this case is the anterior pedal-pedal commissure, via extracellular recordings. In Tritonia and Pleurobranchaea, C2 identity could be confirmed by its involvement in the dorsal-ventral swim motor pattern. Finally, in experiments where C2 identity was not certain, the soma was filled with the biotinylated tracer biocytin $(2.5 \%$ dissolved in $0.75 \mathrm{M} \mathrm{KCl}$ ) (Invitrogen) or Neurobiotin (2-4\% dissolved in $0.75 \mathrm{M} \mathrm{KCl}$ ) (Vector Laboratories) and processed for FMRFamide and/or Small Cardioactive Peptide B $\left(\mathrm{SCP}_{\mathrm{B}}\right)$ immunoreactivity (see below). The axon projection in conjunction with FMRFamide and $\mathrm{SCP}_{\mathrm{B}}$ immunoreactivity uniquely identifies C2 across species (Lillvis et al., 2012).

There are three DSIs found in a cluster in a characteristic location in each species (Getting et al., 1980; Jing and Gillette, 1999; Tian et al., 2006; Newcomb and Katz, 2007). Upon impaling DSI with a microelectrode, it shows characteristic spiking activity, action potential shape, and synaptic input that distinguish it from neighboring neurons. In Tritonia, DSI (www.neuronbank.org/Tri0001043) was identified preliminarily by soma position, size, and its mottled dark pigmentation. In Pleurobranchaea, the axon projection of DSI (As, www.neuronbank. org/Ple0002605) could be confirmed by monitoring the contralateral anterior cerebral-pedal connective. In Tritonia and Pleurobranchaea, DSI 
could be uniquely identified simply by its involvement in the dorsalventral swim motor pattern. The DSI soma was filled with the biotinylated tracer biocytin or Neurobiotin after the experiment and processed for 5-HT immunohistochemistry (see below). Soma position and axon projection in conjunction with 5-HT immunoreactivity uniquely identify DSI across species (Newcomb and Katz, 2007), allowing the homolog in Hermissenda (CPT, www.neuronbank.org/Her0002693) to be identified. 5-HT immunoreactivity was also used to confirm DSI identity in all Tritonia and Pleurobranchaea preparations in which identity was not confirmed by involvement in the swim motor pattern.

Immunohistochemistry. Biocytin or Neurobiotin processing and immunohistochemistry procedures were identical to those reported in Lillvis et al., 2012. Briefly, after fixation, brains were washed and incubated in one or more of the following primary antisera: rabbit antiFMRFamide (Immunostar, lot \#719001) or anti-serotonin (Invitrogen, lot \#541317) antiserum diluted 1:1000 and/or mouse monoclonal anti$\mathrm{SCP}_{\mathrm{B}}$ (courtesy of Stephen Kempf) diluted 1:20 in antiserum diluent (0.5\% Triton X-100, 1\% normal goat serum, and 1\% BSA in PBS (50 mM $\mathrm{Na}_{2} \mathrm{HPO}_{4}$ in $140 \mathrm{~mm} \mathrm{NaCl}$, pH 7.2). Streptavidin-AlexaFluor-594 conjugate (1:50-1:200, Invitrogen) was also added to visualize the biotinylated tracer. Brains were then washed and incubated in goat anti-rabbit and/or goat anti-mouse antiserum conjugated to AlexaFluor-488, AlexaFluor-594 (Invitrogen), or DyLight 405 (Jackson ImmunoResearch Laboratories) diluted 1:100 in antiserum diluent. Brains were then washed, dehydrated, and mounted on a slide to visualize soma immunohistochemistry and axon projection.

Electrophysiology. Intracellular recordings were obtained using 10-80 $\mathrm{M} \Omega$ glass microelectrodes filled with $3 \mathrm{M} \mathrm{KCl}$ connected to Axoclamp 2B amplifiers (Molecular Devices). Extracellular suction electrode recordings were obtained by drawing individual nerves into polyethylene tubing filled with saline connected to a differential AC amplifier (model 1700, A-M Systems). Both intracellular and extracellular recordings were digitized $(>1 \mathrm{kHz})$ with a 1401 Plus using Spike2 software (Cambridge Electronic Design).

In the isolated brain, body wall nerve stimulation was used to activate sensory neurons in a standard protocol (Frost and Katz, 1996). Pedal nerves 2 or 3 (PdN2/PdN3) were used in Tritonia and Hermissenda (Newcomb et al., 2006). The body wall nerve was used in Pleurobranchaea (Jing and Gillette, 1999). The stimulus parameters were systematically varied in an effort to thoroughly test whether the DSI and C2 homologs were capable of producing the bursting activity that underlies dorsal-ventral swimming (1-5 s, 5-20 ms pulses, 5-20 Hz, 5-50 V).

High divalent cation (HiDi) saline, which raises the threshold for spiking and reduces spontaneous neural firing, was used for all modulation experiments. The composition of HiDi saline was (in mM): $285 \mathrm{NaCl}, 10$ $\mathrm{KCl}, 25 \mathrm{CaCl}_{2}, 125 \mathrm{MgCl}_{2}, 11 \mathrm{D}$-glucose, and 10 HEPES, $\mathrm{pH}$ 7.5. All drugs used in the modulation experiments were dissolved in HiDi saline. Superfusion rate for these experiments was $\sim 1 \mathrm{ml} / \mathrm{min}$.

In Tritonia, DSI modulation of C2 is presynaptic (Katz and Frost, 1995b); therefore, neurons in the pedal ganglion that are postsynaptic targets of $\mathrm{C} 2$ were used as convenient monitors of the modulation. The following standard stimulus protocol was used to test DSI modulation of C2 synapses. C2, DSI, and a pedal target neuron were impaled with intracellular microelectrodes. Two electrodes were inserted into the postsynaptic target of $\mathrm{C} 2$ : one electrode monitored the membrane potential and the other electrode was used to inject current to hold the membrane potential near $-70 \mathrm{mV}$ to prevent action potential firing. C2 was stimulated intracellularly to fire four action potentials every $2 \mathrm{~min}$ (four $20 \mathrm{~ms}$ pulses at $20 \mathrm{~Hz}$ ). DSI was stimulated intracellularly to fire 50 action potentials (fifty $20 \mathrm{~ms}$ pulses at $5 \mathrm{~Hz}$ ) that ended $3 \mathrm{~s}$ before every other $\mathrm{C} 2$ stimulus.

For 5-HT bath-application experiments, C2 was stimulated to fire four action potentials every $2 \mathrm{~min}$. After baseline postsynaptic potential amplitude was established, $100 \mu \mathrm{M}$ 5-HT (Sigma Aldrich) was superfused into the recording dish. For experiments testing whether methysergide blocked DSI modulation, the DSI modulation of C2 protocol was used; $50 \mu \mathrm{M}$ methysergide (dissolved in DMSO at 1:1000 total volume; Sigma Aldrich) was superfused into the recording dish. For the experiment testing whether methysergide blocked the Pleurobranchaea swim motor pattern in the isolated brain, a body wall nerve was stimulated every 10 min in saline; $50 \mu \mathrm{M}$ methysergide (in 1:1000 DMSO) in saline was superfused into the recording dish.

Data acquisition, analysis, and statistics. Data acquisition and analysis were performed with Spike2 software (Cambridge Electronic Design) and Sigma Plot (Jandel Scientific). The amplitudes of the synaptic potentials were measured by subtracting the baseline membrane potential before $\mathrm{C} 2$ stimulation from the peak membrane potential after $\mathrm{C} 2 \mathrm{stim}$ ulation. The percentage of DSI modulation was calculated by subtracting the amplitude of the $\mathrm{C} 2$-evoked synaptic potential immediately before a DSI spike train (C2 alone EPSP) from the amplitude of the C2-evoked EPSP when C2 was stimulated immediately after the DSI train (DSI + C2 EPSP) and dividing by the mean amplitude of the EPSP when C2 was stimulated alone as shown in this formula:

$$
\text { \%DSI mod. }=\left(\frac{\mathrm{DSI}+\mathrm{C} 2 \mathrm{EPSP}-\mathrm{C} 2 \text { alone EPSP }}{\text { mean C2 alone EPSP }}\right) * 100
$$

To determine whether a relationship between swim strength and the

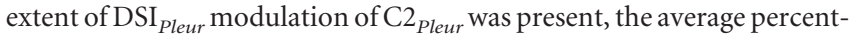

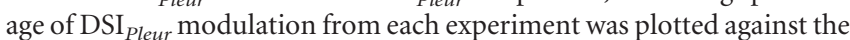
number of swim cycles exhibited in Pleurobranchaea on the day of the experiment.

The percentage modulation caused by 5 -HT bath application was calculated by dividing the average of 10 consecutive synaptic amplitudes at the time of the maximum effect of 5-HT by the average of the 10 consecutive baseline synaptic amplitudes immediately before 5-HT application.

The effect of control and methysergide injections on Pleurobranchaea swimming was tested using a one-way repeated measures ANOVA with post hoc pairwise multiple comparisons using the Holm-Sidak method. Pairwise comparisons of the percentage of DSI modulation in swimming and nonswimming Pleurobranchaea were made using a Student's $t$ test. Pairwise comparisons of the percentage of 5-HT modulation in swimming and nonswimming Pleurobranchaea were made using a MannWhitney rank-sum test as the data failed the Kolmogorov-Smirnov test of normality. Pairwise comparisons of the effect of methysergide on DSI modulation in Pleurobranchaea were made using paired Student's $t$ tests. Comparisons of the amplitude of C2-evoked EPSPs when C2 was stimulated alone to when C2 was stimulated after DSI in all species were made using paired Student's $t$ tests. Comparisons of the amplitude of C2evoked EPSPs in saline and in 5-HT were made using paired Student's $t$ tests or Wilcoxon signed rank tests when the data failed the KolmogorovSmirnov test of normality. Comparisons of the percentages of DSI and 5-HT modulation across all groups were made using a one-way ANOVA with post hoc pairwise multiple comparisons using the Holm-Sidak or Dunn's method. Dunn's method was used when comparing the results of 5-HT bath application where the data failed the Kolmogorov-Smirnov test of normality. In all cases where data failed the test of normality, the median values of each species were compared. Results are expressed as the mean \pm SEM unless stated otherwise. In all cases, $p<0.05$ was considered significant.

\section{Results}

DSI and serotonin enhance C2 synaptic strength in Tritonia

We replicated previous results in Tritonia (Katz et al., 1994; Katz and Frost, 1995a,b) by demonstrating that DSI $_{T r i}$ enhanced the strength $\mathrm{C} 2_{T r i}$-evoked synapses. Using a standard stimulus protocol (Materials and Methods), DSI ${ }_{T r i}$ increased the amplitude of $\mathrm{C} 2{ }_{T r i}$-evoked synaptic potentials by an average of $107.4 \pm 26.2 \%$ $(n=5)$. The average amplitude of the $\mathrm{C} 2_{T r i}$-evoked EPSP when $\mathrm{C} 2_{T r i}$ was stimulated alone was $3.2 \pm 1.2 \mathrm{mV}$ compared with $5.9 \pm 1.9 \mathrm{mV}$ when $\mathrm{C} 2_{T r i}$ was stimulated after DSI, a significant increase (paired Student's $t$ test, $t_{(4)}=-3.32, p=0.029$; Fig. $2 A$ ). We also replicated prior results showing that bath application of 5-HT mimics the DSI ${ }_{T r i}$ modulation (Katz et al., 1994; Katz and Frost, 1995a). Here, $100 \mu \mathrm{M}$ 5-HT increased the size of $\mathrm{C} 2{ }_{T r i}$-evoked synaptic potentials by $137.0 \pm 8.0 \%(n=2$; Fig. $2 B)$. The average amplitude of the $\mathrm{C} 2_{T r i}$-evoked EPSP in HiDi 
saline was $3.0 \pm 2.1 \mathrm{mV}$ compared with $7.0 \pm 4.7 \mathrm{mV}$ in $100 \mu \mathrm{M} 5-\mathrm{HT}(n=2)$.

\section{DSI and serotonin enhance C2 synaptic strength in Pleurobranchaea}

We found that using the same stimulus protocol as in Tritonia, DSI Pleur $_{\text {increased }}$ the amplitude of $\mathrm{C} 2$ Pleur -evoked synapses by $112.4 \pm 23.7 \%(n=10)$ (Fig. $2 C)$. The average amplitude of the $\mathrm{C} 2_{\text {Pleur }}$-evoked EPSP when $\mathrm{C} 2$ Pleur was stimulated alone was $2.7 \pm 0.7 \mathrm{mV}$ compared with $5.0 \pm$ $1.1 \mathrm{mV}$ when $\mathrm{C} 2_{\text {Pleur }}$ was stimulated after DSI $_{\text {Pleur }}$, significant increase (paired Student's $t$ test, $\left.t_{(9)}=-3.45, p=0.007\right)$.

Additionally, bath application of 100 $\mu \mathrm{M}$ 5-HT increased the amplitude of $\mathrm{C} 2_{\text {Pleur }}$-evoked synaptic potentials by an average of $68.5 \pm 16.1 \%(n=21)$ (Fig. $2 D$ ). The average amplitude of the $\mathrm{C} 2$ Pleur $^{-}$ evoked EPSP in HiDi saline was $4.3 \pm 0.8$ $\mathrm{mV}$ compared with $6.1 \pm 0.9 \mathrm{mV}$ in 100 $\mu \mathrm{M}$ 5-HT, a significant increase (paired Student's $t$ test, $\left.t_{(20)}=-3.76, p=0.001\right)$. Thus, Pleurobranchaea, which responds to an electric shock with a swimming behavior that is analogous to that of Tritonia, exhibited similar neuromodulation intrinsic to the swim CPG.

However, some experiments showed markedly reduced levels of DSI $\mathrm{Pleur}_{\text {and }}$ and serotonergic neuromodulation compared with others and thus reduced the average modulatory effect. This encouraged an investigation of the possible causes for the variable results.

\section{The Pleurobranchaea swimming behavior exhibits variability} Unlike Tritonia, which reliably produces the rhythmic motor pattern in vivo in response to starfish tube feet (Willows, 1967), concentrated $\mathrm{NaCl}$ solution (Getting, 1976), or electric shock (Mongeluzi et al., 1998), Pleurobranchaea individuals exhibit heterogeneity in their propensity to swim (Jing and Gillette, 1995, 1999). In our hands, electric shock was the most reliable trigger for Pleurobranchaea swimming. Even so, 18 of 61 (30\%) individual Pleurobranchaea tested failed to produce a single swim cycle in response to electric shock even when stimulated repeatedly. Of the animals that did swim in response to electric shock, the average number of swim cycles observed by each animal was 3.1 with an average coefficient of variation of $0.80(n=43)$. The propensity to swim varied daily; on some days, a given animal would swim, but on other days, it would not (Fig. 3). This variability allowed a natural experiment in which we could test whether the strength of swimming correlated with the extent that $\mathrm{DSI}_{\text {Pleur }}$ modulated $\mathrm{C} 2_{\text {Pleur }}$ synapses.

\section{The extent of neuromodulation is related to the duration of swimming in Pleurobranchaea}

We found that animals that did not swim on the day of testing tended to exhibit little or no modulation (Fig. 4A). The difference was not the result of a problem with $\mathrm{DSI}_{\text {Pleur }}$ stimulation; DSI $_{\text {Pleur }}$-evoked EPSPs followed one-for-one with DSI ${ }_{\text {Pleur }}$ spikes regardless of the number of swim cycles expressed $(n=5$ for nonswimmers, $n=5$ for swimmers; Fig. $4 B$ ). The extent of $\mathrm{DSI}_{\text {Pleur }}$ modulation of $\mathrm{C} 2_{\text {Pleur }}$ synapses correlated with the maxi-

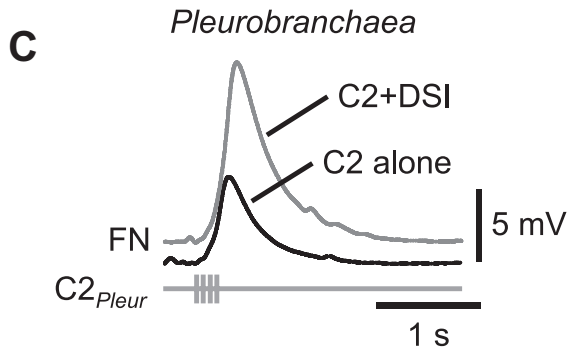

D

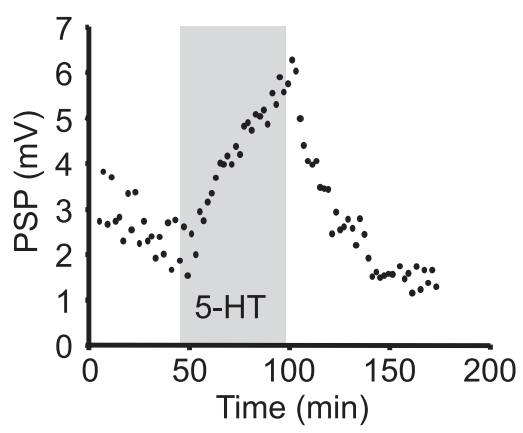

Figure 2. DSI and 5-HT modulated (2-evoked synaptic potentials in Tritonia and Pleurobranchaea.A, C, Stimulating C2 (bottom gray lines) elicited an EPSP (black trace) in a postsynaptic follower neuron (FN) in Tritonia $(\boldsymbol{A})$ and Pleurobranchaea $(\boldsymbol{C})$. Stimulating other for better visibility. B, D, Bath applying $100 \mu \mathrm{m} 5$-HT increased the amplitude of (2-evoked EPSPs in Tritonia $(\boldsymbol{B})$ and Pleurobranchaea (D). The amplitude of the C2-evoked EPSPs was plotted over time.

mum number of swim cycles observed on the day of testing with the maximum modulation near 200\% (Fig. 4C). For animals that swam fewer than two cycles (which we considered nonswimmers), DSI ${ }_{\text {Pleur }}$ caused only a $61.4 \pm 26.8 \%$ increase in $\mathrm{C}_{\text {Pleur }}$-evoked EPSP amplitude $(n=5)$, whereas there was a $163.4 \pm 22.3 \%$ increase in $\mathrm{C}_{\text {Pleur }}{ }^{-}$ evoked EPSP amplitude in individuals that swam two or more cycles $(n=5)$. This difference between the levels of modulation in swimmers compared with nonswimmers was significant (Student's $t$ test, $\left.t_{(8)}=2.92, p=0.019\right)$. In nonswimming Pleurobranchaea, the average amplitude of the $\mathrm{C} 2_{\text {Pleur }}$-evoked EPSP when $\mathrm{C} 2_{\text {Pleur }}$ was stimulated after $\operatorname{DSI}_{\text {Pleur }}(4.4 \pm 1.7 \mathrm{mV})$ was not significantly different from when $\mathrm{C} 2_{\text {Pleur }}$ was stimulated alone $(3.2 \pm 1.3 \mathrm{mV}$ ) (paired Student's $t$ test, $\left.t_{(4)}=-1.82, p=0.144\right)$. In swimming Pleurobranchaea, however, the average amplitude of the $\mathrm{C} 2_{\text {Pleur }}$-evoked EPSP when $\mathrm{C} 2_{\text {Pleur }}$ was stimulated after DSI $\mathrm{Dleur}_{\text {was }} 5.6 \pm 1.6 \mathrm{mV}$, which was significantly larger than the average amplitude of $2.2 \pm$ $0.6 \mathrm{mV}$ when $\mathrm{C} 2_{\text {Pleur }}$ was stimulated alone (paired Student's $t$ test, $t_{(4)}$ $=-3.46, p=0.026)$. The lack of modulation in nonswimmers appears to be caused by a decreased sensitivity to 5-HT. In animals that did not swim, bath-applied 5-HT caused little or no modulation of $\mathrm{C}_{\text {Pleur }}$ synaptic strength (Fig. $4 D$ ). The mean value of the increase in $\mathrm{C} 2$ Pleur -evoked EPSP amplitude resulting from 5-HT was $32.3 \pm$ $20.1 \%$ (median, $15.4 \%)$ in nonswimmers $(n=11)$ compared with $101.4 \pm 20.8 \%$ (median, 92.0\%) in swimmers $(n=10)$ (MannWhitney rank-sum test, $t_{(19)}=71.00, p=0.007$ ). The effect of 5-HT on $\mathrm{C}_{\text {Pleur }}$-evoked EPSP amplitude was not significant in nonswimming Pleurobranchaea but was significant in swimming individuals. In nonswimming individuals, the average amplitude of the $\mathrm{C}_{\text {Pleur }}{ }^{-}$ evoked EPSP in HiDi saline was $5.4 \pm 1.3 \mathrm{mV}$ (median of $4.7 \mathrm{mV}$ ) compared with $6.5 \pm 1.4 \mathrm{mV}$ (median of $6.0 \mathrm{mV}$ ) in $100 \mu \mathrm{M}$ 5-HT (Wilcoxon signed rank test, $\mathrm{Z}(10)=1.69, p=0.102$ ). Whereas, in swimming Pleurobranchaea, the average amplitude of the $\mathrm{C}_{\text {Pleur }}{ }^{-}$ evoked EPSP in HiDi saline was $3.0 \pm 0.7 \mathrm{mV}$ compared with $5.7 \pm$ $1.4 \mathrm{mV}$ in $100 \mu \mathrm{M}$ 5-HT (paired Student's $t$ test, $t_{(9)}=-4.89, p<$ $0.001)$. 

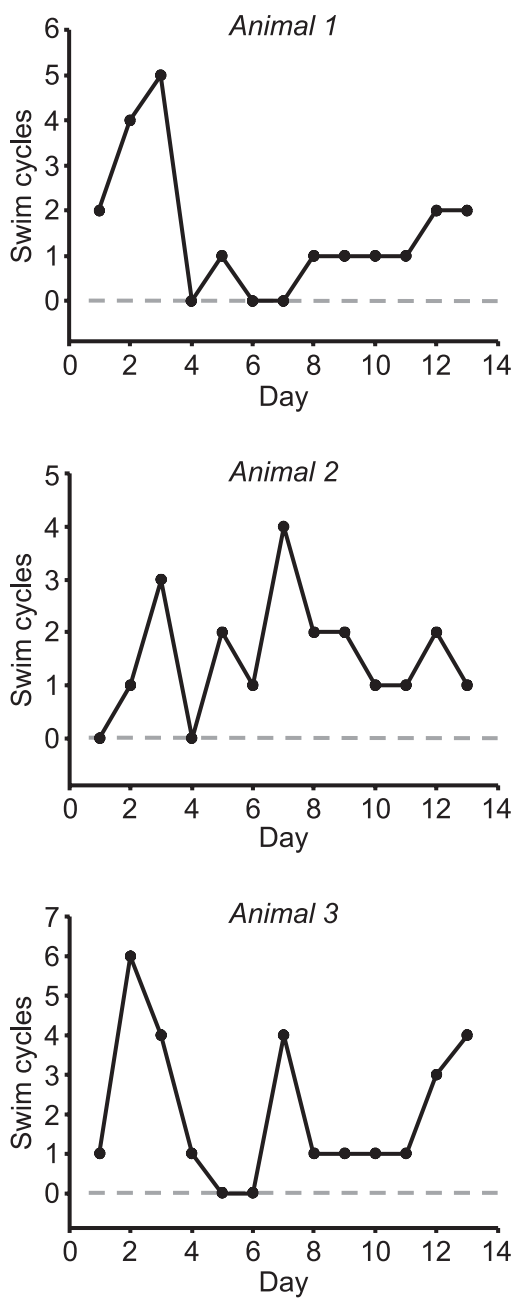

Figure 3. Individual Pleurobranchaea varied daily in their ability to produce a swim. Three representative examples of the daily variability in the swimming behavior of individual Pleurobranchaea specimens. The number of swim cycles elicited from an electrical stimulus to the body wall changed over a period of days.

\section{Methysergide reduces the extent of neuromodulation}

In Tritonia, the 5-HT receptor antagonist methysergide reduces the modulation of $\mathrm{C} 2_{T r i}$-evoked synaptic strength by 5 -HT and DSI $_{\text {Tri }}$ (Katz and Frost, 1995a). We found that, in Pleurobranchaea, applying $50 \mu \mathrm{M}$ methysergide reduced the extent of the $\mathrm{DSI}_{\text {Pleur }}$ modulation of $\mathrm{C} 2_{\text {Pleur }}$ synaptic strength (Fig. 5). In this set of experiments, $\mathrm{DSI}_{\text {Pleur }}$ enhanced $\mathrm{C} 2_{\text {Pleur }}$ synaptic strength by an average of $108.8 \pm 18.4 \%$ before applying methysergide. Methysergide reduced the enhancement to $26.7 \pm$ $11.3 \%$, a significant reduction (paired Student's $t$ test, $n=5$, $\left.t_{(4)}=3.46, p=0.026\right)$. Thus, in both Tritonia and Pleurobranchaea, methysergide inhibits receptors responsible for DSI modulatory actions.

\section{Methysergide blocks Pleurobranchaea swimming}

It was previously shown that injection of methysergide into the body cavity of Tritonia inhibited swimming (McClellan et al., 1994). We observed a similar effect in Pleurobranchaea (Fig. 6, च). For these experiments, baseline swimming in response to electric shock was measured for at least 4 trials. Any individual that did not show consistent swimming in response to this stimulus during the baseline tests was removed from the experiment. The latency to the effect of methysergide varied across individu- als, but on average the number of swim cycles was significantly reduced from baseline measurements by $2 \mathrm{~h}$ after the injection (one-way repeated-measures ANOVA, Holm-Sidak pairwise comparisons, $\left.n=8, F_{(14,94)}=8.5, p<0.001\right)$. The next day, there was a recovery of swimming behavior in response to electric shock. Control vehicle injections never showed a change in the number of swim cycles (one-way repeated-measures ANOVA, Holm-Sidak pairwise comparisons, $n=6, F_{(13,63)}=0.48, p=$ 0.927) (Fig. 6, ○).

Whereas the isolated Tritonia brain preparation reliably produces a swim motor pattern in response to electrical stimulation of a body wall nerve, we rarely encountered an isolated Pleurobranchaea brain preparation that repeatedly and reliably produced a swim motor pattern for the time that it would take to test methysergide. However, in one such case, bath application of methysergide also blocked expression of the swim motor pattern, which recovered after washout of the antagonist.

\section{5-HT lowers the threshold for Pleurobranchaea swimming}

In Tritonia, injection of 5-HT in vivo reliably evokes dorsalventral swimming (McClellan et al., 1994). We repeated these experiments and confirmed that 5-HT injection into the body cavity of Tritonia caused vigorous swimming $(n=2)$, whereas control seawater injections did not $(n=2)$. In Pleurobranchaea, 5 -HT injection induced weak dorsal and ventral flexions $(n=4)$. Additionally, the threshold for swim induction was greatly reduced; in Pleurobranchaea, electrical stimulation of the skin generally is required to evoke swimming, but after 5-HT injection simply touching the animal triggered vigorous dorsal-ventral swims in three of the four animals tested. No behavioral effects were observed from control seawater injections into Pleurobranchaea $(n=4)$.

In summary, as in Tritonia, $\mathrm{DSI}_{\text {Pleur }}$ modulation of $\mathrm{C} 2_{\text {Pleur }}$ was present and serotonergic modulation was necessary for Pleurobranchaea to produce a swim in response to electrical stimulation. Moreover, individual variation in swimming correlated with the extent that DSI $I_{\text {Pleur }}$ modulated $\mathrm{C} 2_{\text {Pleur }}$ synapses. These results suggest that serotonergic modulation within the CPG circuit is necessary for expression of the dorsal-ventral swimming behavior and its neural basis in Pleurobranchaea.

\section{DSI and serotonin modulation of C2 synapses in Hermissenda} The vast majority of species in the Nudipleura do not swim (Newcomb et al., 2012). We tested whether DSI and serotonergic modulation were present in $H$. crassicornis, a species that does not produce dorsal-ventral swimming (Lillvis et al., 2012). Nerve stimuli that evoke swim motor patterns in the isolated brains of Tritonia and Pleurobranchaea (Fig. 1) did not elicit rhythmic bursting in Hermissenda as monitored in the homologs of the CPG neurons, $\mathrm{C}_{\text {Herm }}$ and $\mathrm{DSI}_{\text {Herm }}(n=29)$ (Fig. $7 A$ ).

Like its homologs in Tritonia and Pleurobranchaea, the Hermissenda DSI is serotonergic (Tian et al., 2006). However, using the same experimental protocol as in Tritonia and Pleuro-

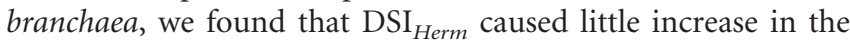
amplitude of $\mathrm{C}_{2 \mathrm{Herm}}$-evoked synaptic potentials. There was a minor increase of only $5.4 \pm 1.8 \%(n=5)$ (Fig. $7 B)$. The mean PSP amplitude when $\mathrm{C} 2{ }_{\text {Herm }}$ was stimulated alone was $13.1 \pm 5.5 \mathrm{mV}$ and $13.6 \pm 5.6 \mathrm{mV}$ when it was stimulated after $\operatorname{DSI}_{\text {Herm }}$ (paired Student's $t$ test, $t_{(4)}=-2.78, p=0.05$ ). The lack of an effect of $\mathrm{DSI}_{\mathrm{Herm}}$ on $\mathrm{C} 2_{\mathrm{Herm}}$ synaptic strength was not the result of the

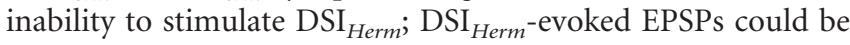
observed in the $\mathrm{C} 2_{\text {Herm }}$ postsynaptic target $(n=3)$ (Fig. $7 C$ ). 
The absence of modulation can be accounted for by an absence in the response to 5-HT. Bath application of 5-HT did not enhance $\mathrm{C} 2{ }_{\mathrm{Herm}}$ synaptic strength and actually caused a small reduction in most preparations (mean of $-15.5 \pm 6.9 \%$ and median of $-6.4 \%, n=12$; Fig. $7 D)$. The

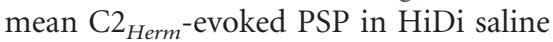
was $12.4 \pm 3.0 \mathrm{mV}$ (median of $9.4 \mathrm{mV}$ ) compared with $9.3 \pm 2.3 \mathrm{mV}$ (median of $6.8 \mathrm{mV}$ ) in $100 \mu \mathrm{M}$ 5-HT (Wilcoxon signed rank test, $\mathrm{Z}(11)=-2.82, p=$ 0.002).

In Hermissenda, 5-HT injections did not induce dorsal-ventral swimming. Instead, 5-HT injection induced noticeable movement of cerata $(n=5)$ and in some cases induced rhythmic left-right flexions $(n=3$ of 5$)$. No behavioral effects were observed from control seawater injections $(n=3)$.

\section{Discussion}

\section{Similar neuromodulatory actions for similar behaviors}

These experiments show that two species with independently evolved swimming behaviors share the same neuromodulatory actions, whereas a species that does not display the behavior lacks the neuromodulation. Tritonia and Pleurobranchaea both exhibit escape swimming responses consisting of dorsal and ventral body flexions (Willows, 1967; Gillette et al., 1991), whereas Hermissenda does not. In both Tritonia and swimming Pleurobranchaea, bath application of 5-HT or stimulation of the serotonergic DSI (As in Pleurobranchaea) enhanced the strength of synapses made by C2 (A1 in Pleurobranchaea). In contrast, in Hermissenda, the application of 5-HT or stimulation of $\mathrm{DSI}_{\mathrm{Herm}}$ (CPT) did not modulate the strength of $\mathrm{C}_{2 \mathrm{Herm}}$ synapses. Tritonia and Pleurobranchaea exhibited significantly more modulation by DSI (Fig. 8A) (one-way ANOVA, Holm-Sidak pairwise comparisons, $\left.F_{(3,16)}=9.46, p<0.001\right)$ and bath-applied 5-HT (Fig. 8B) (Kruskal-Wallis one-way ANOVA on ranks, Dunn's pairwise comparisons, $\mathrm{H}(3)=25.58, p<0.001)$ than did Hermissenda.

Serotonergic neuromodulation is necessary for swimming in both Tritonia and Pleurobranchaea. The 5-HT receptor antagonist methysergide blocked both the neuromodulation of $\mathrm{C} 2$ synaptic strength and the production of swimming in Pleurobranchaea as it does in Tritonia (McClellan et al., 1994; Katz and Frost, 1995a). 5-HT is also sufficient to trigger dorsal-ventral flexion swimming in both species, but not in Hermissenda. These results correlating the presence of serotonergic neuromodulation with species that swim with dorsal-ventral body flexions suggest that serotonergic neuromodulation plays a key role in the production of this behavior.

Although the results demonstrate that 5-HT plays a crucial role in the production of the swim in both Tritonia and Pleurobranchaea, this does not imply that only $\mathrm{C} 2$ synapses are involved. Methysergide and 5-HT likely act at many sites throughout the brain. For example, in Tritonia, DSI and 5-HT also modulate the synaptic strength of another swim CPG neuron (VSI) (Sakurai and Katz, 2003, 2009; Sakurai et al., 2006). The homolog of VSI has not
B

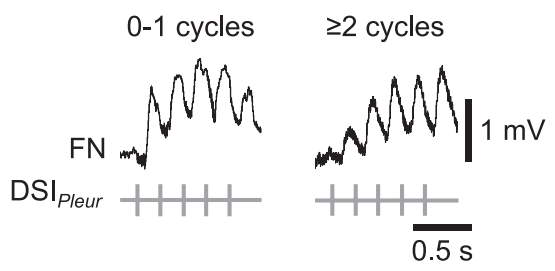

D

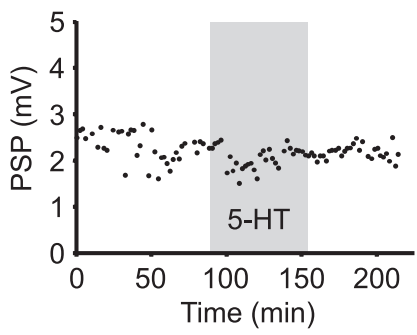

Individual variability in Pleurobranchaea swimming correlated with DSI and 5-HT modulation of C2-evoked synaptic mean values by the equation $y=36+151.7^{*}(x / 0.9 x)$ with an $R^{2}$ value of 0.58 . D. Example showing that bath application of 100

A

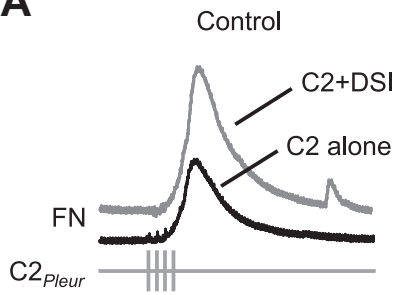

B

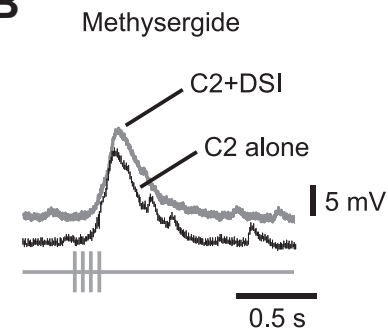

Figure 5. Methysergide blocked DSI modulation of (2 synapses in Pleurobranchaea. A, Control: Stimulating $\mathrm{C}_{\text {pleur }}$ elicited an EPSP (black trace) in a postsynaptic follower neuron (FN). Stimulating DSI Pleur $_{3} 3 \mathrm{~s}$ before the $\mathrm{C}_{\text {Pleur }}$ stimulation increased the amplitude of the $\mathrm{C}_{\text {Pleur }}{ }^{-}$ evoked EPSP (gray trace). $\boldsymbol{B}$, In the presence of $50 \mu \mathrm{m}$ methysergide, the EPSP elicited from $\mathrm{C}_{\text {Pleur }}$ alone (black trace) was similar to the control measurement, but the modulatory effect of DSI Pleur was significantly reduced (gray trace). Traces are vertically offset from each other for better visibility.

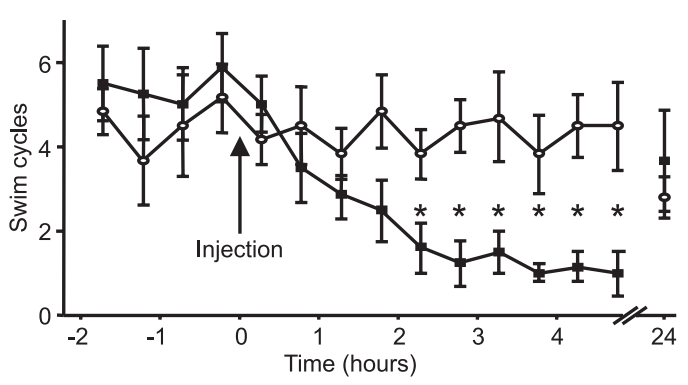

Figure 6. Methysergide inhibited the Pleurobranchaea swimming behavior. The average number of swim cycles (and SEM) is plotted over time. Injection of $10 \mathrm{mg} / \mathrm{L}$ methysergide (arrow) significantly reduced the number of swim cycles $(\square)$ (one-way repeated-measures ANOVA, Holm-Sidak pairwise comparisons, $\left.n=8, F_{(14,94)}=8.54, p<0.001\right)$; the swim recovered overnight. Vehicle control injections $(O)$ did not result in a reduction of swim cycles (one-way repeated-measures ANOVA, Holm-Sidak pairwise comparisons, $n=6, F_{(13,63)}=$ $0.48, p=0.927)$. 

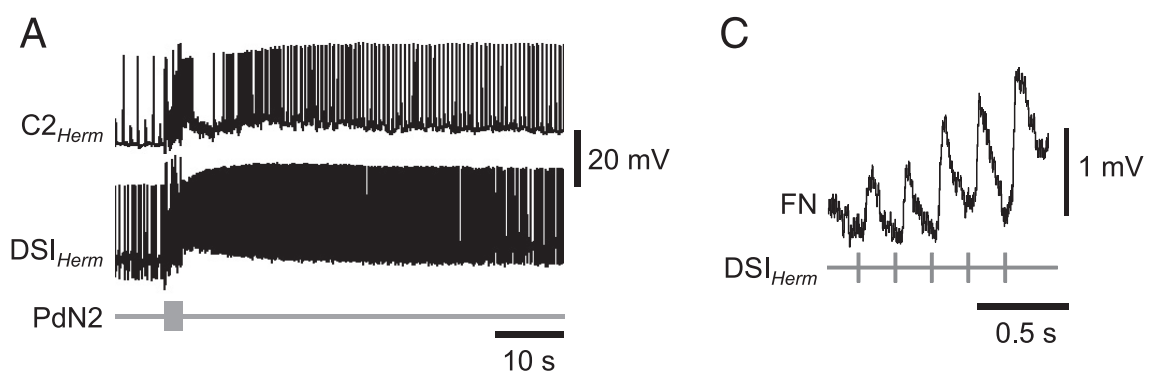

B

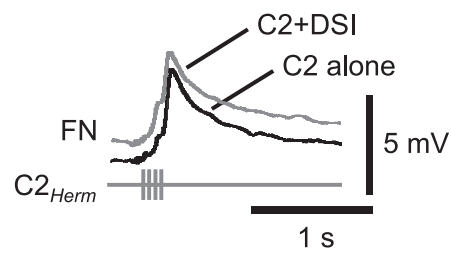

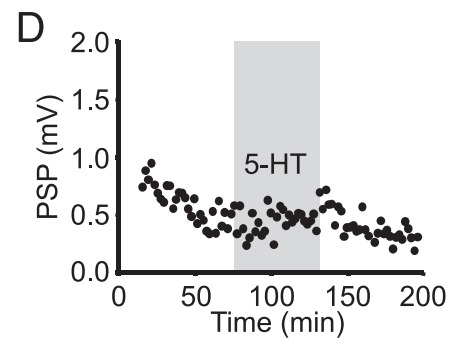

Figure 7. Hermissenda lacked the DSI and 5-HT modulation. A, In Hermissenda, PdN2 stimuli (gray bar) elicited high-frequency

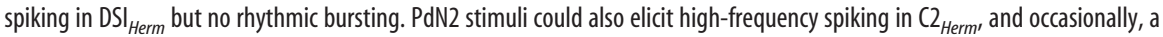
single burst, but no rhythmic bursting. $\boldsymbol{B}$, Stimulating $\mathrm{C}_{\text {Herm }}$ elicited an EPSP (black trace) in a postsynaptic follower neuron (FN). Stimulating $\mathrm{DSI}_{\text {Herm }} 3$ s before the $\mathrm{C}_{\text {Herm }}$ stimulation did not increase the amplitude of the $\mathrm{C}_{\text {Herm }}$-evoked EPSP (gray trace). Traces are vertically offset from each other for better visibility. $C$, The lack of an effect is not the result of failure of DSI ${ }_{\text {Herm }}$ spikes; DSI $_{\text {Herm }}$ evoked one-for-one EPSPs in the FN. D, Bath application of $100 \mu \mathrm{m} 5$-HT did not increase the amplitude of $\mathrm{C2}_{\text {Herm }}$-evoked EPSPs.

been identified in Pleurobranchaea, so this site of modulation cannot be tested yet.

Here we have shown similar neuromodulatory actions underlie similar behaviors. Additionally, the results indicate that the lack of modulation in Hermissenda may be responsible the absence of the swim behavior. There are many examples of species differences in the presence of neuromodulatory transmitters or receptors, some of which have been shown to have implications for behavior (Katz and Harris-Warrick, 1999). For example, in amphibian embryos, species differences in neuromodulation account for differences in swimming (McLean and Sillar, 2004; Merrywest et al., 2004). Species variations in serotonergic neuromodulation have also been correlated with differences in sensitization in aplysiid molluscs (Marinesco et al., 2003; Hoover et al., 2006).

\section{Parallel evolution of neuromodulation underlies independent evolution of behavior}

Phylogenetic evidence suggests that Trito-
A

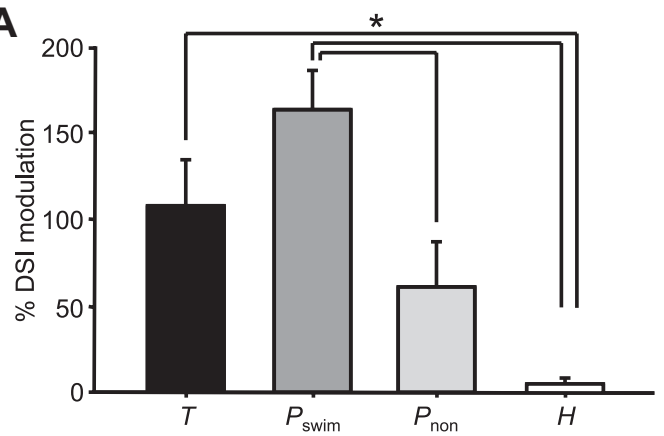

B

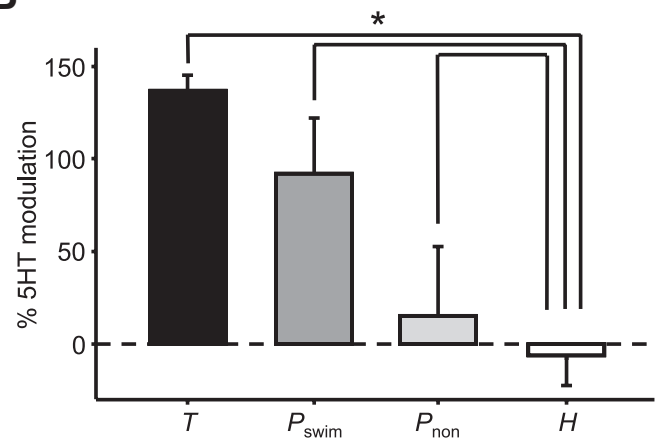

Figure 8. Summary of modulation results across species. $A$, The average percentage increase in C2-evoked EPSPs produced by DSI in Tritonia $(T)$ and swimming Pleurobranchaea $\left(P_{\text {swim }}\right)$ was significantly greater than that in Hermissenda $(H)$. Swimming Pleurobranchaea DSI $P_{P l e u r}$ modulation percentage was also significantly greater than that of nonswimming Pleurobranchaea $\left(P_{\text {non }}\right)$ (one-way ANOVA, Holm-Sidak post hoc pairwise comparisons, $n=5$ for all species, $F_{(3,16)}=9.46, p<0.001$; post hoc comparisons: swimming Pleurobranchaea vs Hermissenda, $p<0.001$; Tritonia vs Hermissenda, $p=0.022$; swimming versus nonswimming Pleurobranchaea, $p=0.018$ ). $\boldsymbol{B}$, The median percentage increase in $\mathrm{C} 2$ synapses in response to 5 -HT bath application was significantly greater in Tritonia and both groups of Pleurobranchaea compared with Hermissenda (Kruskal-Wallis one-way ANOVA on ranks, Dunn's post hoc pairwise comparisons, $n=2$ in Tritonia, 10 in swimming Pleurobranchaea, 11 in nonswimming Pleurobranchaea, 12 in Hermissenda, $\mathrm{H}(3)=25.58, p<0.001)$. nia and Pleurobranchaea evolved dorsal-ventral flexion swimming independently (Newcomb et al., 2012). Both species belong to the monophyletic clade Nudipleura (Waegele and Willan, 2000; Bouchet et al., 2005), which consists of two monophyletic subclades: Pleurobranchomorpha (to which Pleurobranchaea belongs) and Nudibranchia (to which Tritonia and Hermissenda belong). Tritonia and Hermissenda can be further grouped together within the subsubclade, Cladobranchia (Bouchet et al., 2005; Pola and Gosliner, 2010). In total, there are $~ 3000$ species of Nudipleura, the vast majority of which do not swim at all; only 17 species in seven genera have been reported to swim using dorsal-ventral flexions. The distribution of these species in the phylogenetic tree suggests that the behaviors evolved independently at least twice and possibly five times or more (Newcomb et al., 2012).

The results from this study show that the production of this independently evolved behavior in Tritonia and Pleurobranchaea relies on a neuromodulatory mechanism that is absent from at least one species that does not exhibit the behavior. Neurons homologous to DSI and C2 have been identified in several species that do not produce dorsal-ventral swimming (Tian et al., 2006; Newcomb and Katz, 2007; Lillvis et al., 2012), including more distantly related opisthobranchs, such as Aplysia californica (Jing et al., 2007) and Clione limacina (Panchin et al., 1995; Satterlie et al., 1995). Although these two neurons are present, it is not known whether DSI modulates C2 synaptic strength in any of these other species.

The fact that DSI and C2 are found in each member of the clade that has been studied suggests that they are ancestral features. Therefore, the apparent emergence of serotonergic neuromodulation of C2 synapses can be considered an example of parallel evolution, where homologous features undergo similar changes (Sanderson and Hufford, 1996; Wake et al., 2011; Pearce, 2012). Parallel evolution of brain mechanisms has been previously suggested to occur in the evolution of primate precision 
hand movements (Padberg et al., 2007) and butterfly color vision (Frentiu, et al, 2007).

The presence of DSI modulation of C2 synaptic strength may be a mechanism to transform a nonrhythmic network of neurons into a functional CPG. That is, there may be a circuit with the latent ability to form a swim CPG circuit when activated by this neuromodulatory signal. A similar latent circuit was described in voles; prairie vole (Microtus ochrogaster) males exhibit pair bonding behaviors that are absent from meadow voles (Microtus pennsylvanicus) (Young and Wang, 2004; Nair and Young, 2006). However, meadow voles can be transformed to exhibit pair bonding through viral expression of vasopression Vla receptors in ventral pallidum, an area that has high V1a receptor expression levels in prairie voles (Lim et al., 2004). Thus, meadow voles must have a latent ability to form a "pair bonding circuit" that is activated by the expression of V1a receptors in particular neurons.

\section{Individual variability}

Unlike individual Tritonia, which reliably swim in response to salt or electric shock stimuli (Mongeluzi et al., 1998), individual Pleurobranchaea exhibited daily fluctuations in the number of flexion cycles that they produced in response to electric shock. The extent of neuromodulation covaried with the maximum number of cycles on the testing day. Thus, there was a correlation, not just between species that exhibit the behavior and the presence of the modulation, but within a species in the extent of swimming and the extent of modulation. The extent of modulation from DSI in nonswimming Pleurobranchaea was not significantly different from that seen in Hermissenda (Fig. 8A).

We do not know the reason for the neuromodulatory and behavioral variability. It was previously reported that individual Pleurobranchaea differed in their tendency to swim (Jing and Gillette, 1995, 1999), but a longitudinal study to determine whether the same individuals consistently did or did not swim was not reported. The variability reported here was not related to the time of day or feeding state of the animal. Animals were housed in individual plastic containers within a larger aquarium; therefore, it was unlikely to be caused by interactions with each other.

The ability of a modulatory system to change the state of an animal and therefore the expression of a behavior is not unexpected; this is precisely the way that circulating hormones affect behavior. However, we are unaware of another situation in which neuron-toneuron neuromodulatory actions covary with behavior.

\section{Neuron multifunctionality, neuromodulation, and the evolvability of behavior}

Neurons can be multifunctional; both DSI and C2 have other behavioral functions aside from being a part of the dorsal-ventral swim CPG. In Tritonia, Pleurobranchaea, and Aplysia californica, DSI can initiate crawling (Jing and Gillette, 2000; Popescu and Frost, 2002; Jing et al., 2008). In Hermissenda, DSI elicits nonrhythmic foot contractions (Tian et al., 2006). DSI also facilitates feeding in Aplysia californica (Jing et al., 2008) and Pleurobranchaea (Jing and Gillette, 2000), whereas C2 suppresses feeding motor patterns in Pleurobranchaea (Jing and Gillette, 1995). In Clione limacina, a species that swims with rhythmic wing-like flapping, DSI modulates the speed of the swim motor pattern (Panchin et al., 1995; Satterlie and Norekian, 1995).

In Tritonia, C2 may play a role in crawling (Snow, 1982). Such functions could be present in other species as well. Therefore, dynamic neuromodulation of C2 may allow it to participate in distinct behaviors at different times. Such sculpting of multifunc- tional neurons into different functional circuits has been well described in the stomatogastric nervous system of decapod crustaceans (Stein, 2009).

In this way, neuromodulation may be a mechanism that affects the evolvability of behavior as it can allow shared neural circuit components to produce various outputs (Katz, 2011). As discussed above, similar patterns of expression for the vasopressin receptor are hypothesized to underlie independent evolution of analogous social behavior (Young and Wang, 2004). Similar associations between nonapeptide receptor expression and social behavior have also been shown in fish, reptiles, birds, and other mammals, including humans (Donaldson and Young, 2008; Young, 2009; Goodson and Thompson, 2010). This suggests that different species have independently acquired similar neuromodulatory mechanisms to produce similar behavior. We propose such a mechanism here; Tritonia and Pleurobranchaea appear to have independently acquired a similar neuromodulatory mechanism using homologous neurons to produce a similar swim behavior. Thus, parallel evolution of neuromodulation may be a mechanism underlying the independent evolution of behavior.

\section{Notes}

Supplemental material for this article is available at http://neuronbank. org/wiki/. NeuronBank contains descriptions of identified neurons. This material has not been peer reviewed.

\section{References}

Arbas EA, Meinertzhagen IA, Shaw SR (1991) Evolution in nervous systems. Annu Rev Neurosci 14:9-38. CrossRef Medline

Bouchet P, Rocroi JP, Fryda J, Hausdorf B, Ponder W, Valdes A, Waren A (2005) Classification and nomenclator of gastropod families. Malacologia 47:1-368.

Calin-Jageman RJ, Tunstall MJ, Mensh BD, Katz PS, Frost WN (2007) Parameter space analysis suggests multi-site plasticity contributes to motor pattern initiation in Tritonia. J Neurophysiol 98:2382-2398. CrossRef Medline

Clemens S, Katz PS (2003) G protein signaling in a neuronal network is necessary for rhythmic motor pattern production. J Neurophysiol 89: 762-772. Medline

Donaldson ZR, Young LJ (2008) Oxytocin, vasopressin, and the neurogenetics of sociality. Science 322:900-904. CrossRef Medline

Frentiu FD, Bernard GD, Cuevas CI, Sison-Mangus MP, Prudic KL, and Briscoe AD (2007) Adaptive evolution of color vision as seen through the eyes of butterflies. Proc Natl Acad Sci U S A 104 [Suppl 1]:8634-8640. CrossRef Medline

Frost WN, Katz PS (1996) Single neuron control over a complex motor program. Proc Natl Acad Sci U S A 93:422-426. CrossRef Medline

Getting PA (1976) Afferent neurons mediating escape swimming of the marine mollusc, Tritonia. J Comp Physiol 110:271-286. CrossRef

Getting PA (1977) Neuronal organization of escape swimming in Tritonia. J Comp Physiol A Neuroethol Sens Neural Behav Physiol 121:325-342. CrossRef

Getting PA, Lennard PR, Hume RI (1980) Central pattern generator mediating swimming in Tritonia. I. Identification and synaptic interactions. J Neurophysiol 44:151-164. Medline

Gillette R, Saeki M, Huang R-C (1991) Defense mechanisms in notaspid snails: acid humor and evasiveness. J Exp Biol 156:335-347.

Goodson JL, Thompson RR (2010) Nonapeptide mechanisms of social cognition, behavior and species-specific social systems. Curr Opin Neurobiol 20:784-794. CrossRef Medline

Harris-Warrick RM, Marder E (1991) Modulation of neural networks for behavior. Annu Rev Neurosci 14:39-57. CrossRef Medline

Hoover BA, Nguyen H, Thompson L, Wright WG (2006) Associative memory in three aplysiids: correlation with heterosynaptic modulation. Learn Mem 13:820-826. CrossRef Medline

Jing J, Gillette R (1995) Neuronal elements that mediate escape swimming and suppress feeding behavior in the predatory sea slug Pleurobranchaea. J Neurophysiol 74:1900-1910. Medline 
Jing J, Gillette R (1999) Central pattern generator for escape swimming in the notaspid sea slug Pleurobranchaea californica. J Neurophysiol 81:654667. Medline

Jing J, Gillette R (2000) Escape swim network interneurons have diverse roles in behavioral switching and putative arousal in Pleurobranchaea. J Neurophysiol 83:1346-1355. Medline

Jing J, Vilim FS, Weiss KR (2007) Interactions between serotonergic neurons in the locomotor and feeding networks in Aplysia. Soc Neurosci Abstr 289.10.

Jing J, Vilim FS, Cropper EC, Weiss KR (2008) Neural analog of arousal: persistent conditional activation of a feeding modulator by serotonergic initiators of locomotion. J Neurosci 28:12349-12361. CrossRef Medline

Katz PS (1999) Beyond neurotransmission: neuromodulation and its importance for information processing. Oxford, United Kingdom: Oxford UP.

Katz PS (2011) Neural mechanisms underlying the evolvability of behaviour. Philos Trans R Soc Lond B Biol Sci 366:2086-2099. CrossRef Medline

Katz PS, Calin-Jageman R (2008) Neuromodulation. In: New encyclopedia of neuroscience (Squire LR, ed), pp 497-503. San Diego: Academic.

Katz PS, Frost WN (1995a) Intrinsic neuromodulation in the Tritonia swim CPG: serotonin mediates both neuromodulation and neurotransmission by the dorsal swim interneurons. J Neurophysiol 74: 2281-2294. Medline

Katz PS, Frost WN (1995b) Intrinsic neuromodulation in the Tritonia swim CPG: the serotonergic dorsal swim interneurons act presynaptically to enhance transmitter release from interneuron C2. J Neurosci 15:60356045. Medline

Katz PS, Harris-Warrick RM (1999) The evolution of neuronal circuits underlying species-specific behavior. Curr Opin Neurobiol 9:628-633. CrossRef Medline

Katz PS, Getting PA, Frost WN (1994) Dynamic neuromodulation of synaptic strength intrinsic to a central pattern generator circuit. Nature 367: 729-731. CrossRef Medline

Katz PS, Fickbohm DJ, Lynn-Bullock CP (2001) Evidence that the swim central pattern generator of Tritonia arose from a nonrhythmic neuromodulatory arousal system: implications for the evolution of specialized behavior. Am Zool 41:962-975. CrossRef Medline

Lillvis JL, Gunaratne CA, Katz PS (2012) Neurochemical and neuroanatomical identification of central pattern generator neuron homologues in nudipleura molluscs. PLoS ONE 7:e31737. CrossRef Medline

Lim MM, Wang Z, Olazábal DE, Ren X, Terwilliger EF, Young LJ (2004) Enhanced partner preference in a promiscuous species by manipulating the expression of a single gene. Nature 429:754-757. CrossRef Medline

Marinesco S, Duran KL, Wright WG (2003) Evolution of learning in three aplysiid species: differences in heterosynaptic plasticity contrast with conservation in serotonergic pathways. J Physiol 550:241-253. CrossRef Medline

McClellan AD, Brown GD, Getting PA (1994) Modulation of swimming in Tritonia: excitatory and inhibitory effects of serotonin. J Comp Physiol A 174:257-266. CrossRef Medline

McLean DL, Sillar KT (2004) Divergent actions of serotonin receptor activation during fictive swimming in frog embryos. J Comp Physiol A Neuroethol Sens Neural Behav Physiol Neuroethol Sens Neural Behav Physiol 190:391-402. CrossRef Medline

Merrywest SD, McLean DL, Buchanan JT, Sillar KT (2004) Evolutionary divergence in developmental strategies and neuromodulatory control systems of two amphibian locomotor networks. Integr Comp Biol 44:47-56. CrossRef Medline

Mongeluzi DL, Hoppe TA, Frost WN (1998) Prepulse inhibition of the Tritonia escape swim. J Neurosci 18:8467-8472. Medline

Nair HP, Young LJ (2006) Vasopressin and pair-bond formation: genes to brain to behavior. Physiology (Bethesda) 21:146-152. CrossRef Medline

Newcomb JM, Katz PS (2007) Homologues of serotonergic central pattern generator neurons in related nudibranch molluscs with divergent behav- iors. J Comp Physiol A Neuroethol Sens Neural Behav Physiol 193:425443. CrossRef Medline

Newcomb JM, Fickbohm DJ, Katz PS (2006) Comparative mapping of serotonin-immunoreactive neurons in the central nervous systems of nudibranch molluscs. J Comp Neurol 499:485-505. CrossRef Medline

Newcomb JM, Sakurai A, Lillvis JL, Gunaratne CA, Katz PS (2012) Homology and homoplasy of swimming behaviors and neural circuits in Nudipleura (Molluscsa, Gastropoda, Opisthobranchia). Proc Natl Acad Sci U S A 109(Suppl 1): 10669-10676. CrossRef Medline

Padberg J, Franca JG, Cooke DF, Soares JG, Rosa MG, Fiorani M Jr, Gattass R, Krubitzer L (2007) Parallel evolution of cortical areas involved in skilled hand use. J Neurosci 27:10106-10115. CrossRef Medline

Panchin YV, Popova LB, Deliagina TG, Orlovsky GN, Arshavsky YI (1995) Control of locomotion in marine mollusk Clione limacina. VIII. Cerebropedal neurons. J Neurophysiol 73:1912-1923. Medline

Pearce T (2012) Convergence and parallelism in evolution: a neo-Gouldian account. Br J Philos Sci 63:429-448. CrossRef

Pola M, Gosliner TM (2010) The first molecular phylogeny of cladobranchian opisthobranchs (Mollusca, Gastropoda, Nudibranchia). Mol Phylogenet Evol 56:931-941. CrossRef Medline

Popescu IR, Frost WN (2002) Highly dissimilar behaviors mediated by a multifunctional network in the marine mollusk Tritonia diomedea. J Neurosci 22:1985-1993. Medline

Sakurai A, Katz PS (2003) Spike timing-dependent serotonergic neuromodulation of synaptic strength intrinsic to a central pattern generator circuit. J Neurosci 23:10745-10755. Medline

Sakurai A, Katz PS (2009) State-, timing-, and pattern-dependent neuromodulation of synaptic strength by a serotonergic interneuron. J Neurosci 29:268-279. CrossRef Medline

Sakurai A, Darghouth NR, Butera RJ, Katz PS (2006) Serotonergic enhancement of a 4-AP-sensitive current mediates the synaptic depression phase of spike timing-dependent neuromodulation. J Neurosci 26:2010-2021. CrossRef Medline

Sanderson MJ, Hufford L (1996) Homoplasy: the recurrence of similarity in evolution. San Diego: Academic.

Satterlie RA, Norekian TP (1995) Serotonergic modulation of swimming speed in the pteropod mollusc Clione limacina. III. Cerebral neurons. J Exp Biol 198:917-930. Medline

Satterlie RA, Norekian TP, Jordan S, Kazilek CJ (1995) Serotonergic modulation of swimming speed in the pteropod mollusc Clione limacina. I. Serotonin immunoreactivity in the central nervous system and wings. J Exp Biol 198:895-904. Medline

Snow RW (1982) Characterization of the synaptic actions of an interneuron in the central nervous system of Tritonia. J Neurobiol 13:251-266. CrossRef Medline

Stein W (2009) Modulation of stomatogastric rhythms. J Comp Physiol A Neuroethol Sens Neural Behav Physiol 195:989-1009. CrossRef Medline

Taghert PH, Willows AOD (1978) Control of a fixed action pattern by single, central neurons in the marine mollusk, Tritonia diomedea. J Comp Physiol 123:253-259. CrossRef

Tian LM, Kawai R, Crow T (2006) Serotonin-immunoreactive CPT interneurons in Hermissenda: identification of sensory input and motor projections. J Neurophysiol 96:327-335. CrossRef Medline

Waegele H, Willan RC (2000) Phylogeny of the nudibranchia. Zool J Linnean Soc 130:83-181. CrossRef

Wake DB, Wake MH, Specht CD (2011) Homoplasy: from detecting pattern to determining process and mechanism of evolution. Science 331: 1032-1035. CrossRef Medline

Willows AO (1967) Behavioral acts elicited by stimulation of single, identifiable brain cells. Science 157:570-574. CrossRef Medline

Young LJ (2009) Being human: love: neuroscience reveals all. Nature 457: 148. CrossRef Medline

Young LJ, Wang Z (2004) The neurobiology of pair bonding. Nat Neurosci 7:1048-1054. CrossRef Medline 